\title{
Ecological factors associated with dengue fever in a central highlands Province, Vietnam
}

Hau V Pham ${ }^{1,2^{*}}$, Huong TM Doan ${ }^{1}$, Thao $T$ Phan ${ }^{1,2}$ and Nguyen N Tran Minh ${ }^{2}$

\begin{abstract}
Background: Dengue is a leading cause of severe illness and hospitalization in Vietnam. This study sought to elucidate the linkage between climate factors, mosquito indices and dengue incidence.

Methods: Monthly data on dengue cases and mosquito larval indices were ascertained between 2004 and 2008 in the Dak Lak province (Vietnam). Temperature, sunshine, rainfall and humidity were also recorded as monthly averages. The association between these ecological factors and dengue was assessed by the Poisson regression model with adjustment for seasonality.

Results: During the study period, 3,502 cases of dengue fever were reported. Approximately $72 \%$ of cases were reported from July to October. After adjusting for seasonality, the incidence of dengue fever was significantly associated with the following factors: higher household index (risk ratio [RR]: 1.66; 95\% confidence interval [Cl]: 1.62-1.70 per 5\% increase), higher container index (RR: 1.78; 95\% Cl: 1.73-1.83 per 5\% increase), and higher Breteau index (RR: 1.57; 95\% Cl: 1.53-1.60 per 5 unit increase). The risk of dengue was also associated with elevated temperature (RR: $1.39 ; 95 \% \mathrm{Cl}: 1.25-1.55$ per $2^{\circ} \mathrm{C}$ increase), higher humidity (RR: 1.59; 95\% Cl: $1.51-1.67$ per 5\% increase), and higher rainfall (RR: 1.13; 95\% Cl: 1.21-1.74 per $50 \mathrm{~mm}$ increase). The risk of dengue was inversely associated with duration of sunshine, the number of dengue cases being lower as the sunshine increases (RR: 0.76; 95\% Cl: 0.73-0.79 per 50 hours increase).

Conclusions: These data suggest that indices of mosquito and climate factors are main determinants of dengue fever in Vietnam. This finding suggests that the global climate change will likely increase the burden of dengue fever infection in Vietnam, and that intensified surveillance and control of mosquito during high temperature and rainfall seasons may be an important strategy for containing the burden of dengue fever.
\end{abstract}

\section{Background}

Dengue, including dengue fever and dengue haemorrhagic fever, is the most rapidly spreading mosquito-borne viral disease and an increasing public health problem globally $[1,2]$. During the past 50 years, the incidence of dengue has increased by 30 fold, parallel with the increasing geographic expansion from urban to rural areas $[3,4]$. According to current estimates, at least 100 countries are endemic of dengue and about 2.5 billion people are at risk in tropical and subtropical regions, with about 50 million dengue infections occurring annually $[1,2]$. The revised International Health Regulations 2005 included dengue as a disease that may constitute a public health emergency of international concern with implications for health security

\footnotetext{
* Correspondence: pvhau@vnn.vn

${ }^{1}$ Institute of Hygiene and Epidemiology of Tay Nguyen, Dak Lak, Vietnam Full list of author information is available at the end of the article
}

due to disruption and rapid epidemic spread beyond national borders [5].

A key strategy of the dengue control program relies on vector control to reduce viral transmission. A number of ecological, biological and social factors are involved in vector breeding and viral transmission [6]. The impact of global warming on human health, especially in vector-borne diseases, is increasingly becoming a public health concern, because the risk of dengue has been reported to be associated directly or indirectly with seasonal changes in climate $[3,4,7,8]$, and mosquito larval indices $[6,9,10]$.

Despite the existence of a National Dengue Control Program since 1998, dengue remains a major health problem in Vietnam. Dengue fever and dengue hemorrhagic fever are leading causes of hospitalization, accounting for 1,000,866 cases reported in Vietnam

\section{Biomed Central}


during the period 1991-2004, the highest number in the Western Pacific Region [2]. The present study was designed to describe the occurrence of dengue and its associated ecological factors in a Central Highlands province in Vietnam.

\section{Methods}

\section{Study setting}

The study was conducted in Dak Lak, a province located in the Central Highlands region of Vietnam. The region is considered one of the most disadvantaged and remote regions in the country. The province is located from $11^{\circ}$ $30^{\prime}-13^{\circ} 25^{\prime}$ North latitude and $107^{\circ} 30^{\prime}-109^{\circ} 30^{\prime}$ East longitudes and shares a border with Cambodia (Figure 1). Dak Lak has a relatively flat terrain with average altitude of about 500 meters above the sea level. There are two seasons: the rainy season runs from May through October with average rainfall $>100 \mathrm{~mm}$, and the dry season from November through April with rainfall $<100 \mathrm{~mm}$. The annual average rainfall is between 1346 and 2083 $\mathrm{mm}$. Annual average temperature ranges between 22 and 26 degrees Celsius (Table 1).

Dak Lak has a population of 1.74 million, among whom, $30 \%$ are of ethnic minorities. It is primarily an

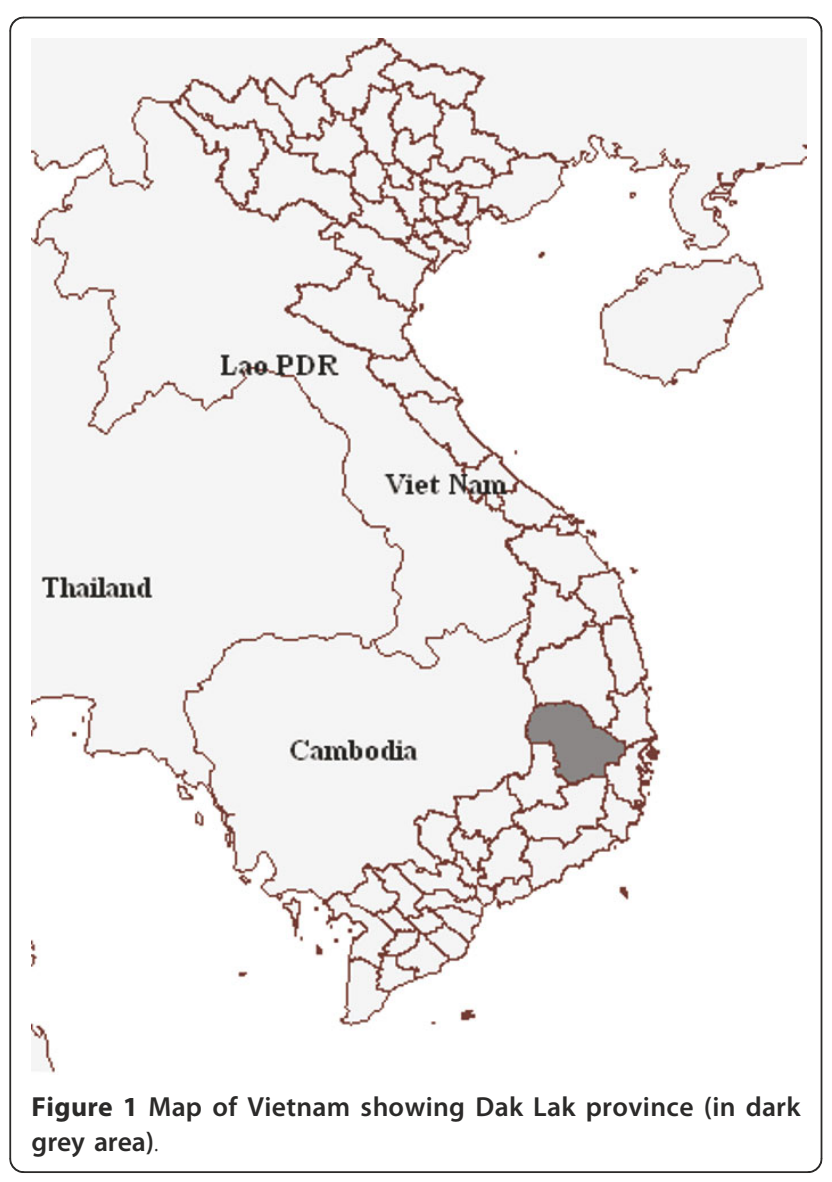

Table 1 Climate conditions in Dak Lak province

\begin{tabular}{lcccc}
\hline Month & $\begin{array}{c}\text { Temp. }^{\left({ }^{\circ}\right.} \\
\mathbf{C}^{\mathbf{a}}\end{array}$ & $\begin{array}{c}\text { Sunshine } \\
\text { (hours) }^{\mathbf{a}}\end{array}$ & $\begin{array}{c}\text { Rainfall } \\
(\mathbf{m m})^{\mathbf{a}}\end{array}$ & $\begin{array}{c}\text { Relative humidity } \\
(\%)^{\mathbf{a}}\end{array}$ \\
\hline Jan & 21.2 & 241 & 3 & 79 \\
Feb & 22.6 & 257 & 1 & 74 \\
Mar & 24.6 & 270 & 47 & 73 \\
Apr & 26.0 & 257 & 78 & 74 \\
May & 26.0 & 216 & 194 & 81 \\
Jun & 25.4 & 202 & 165 & 84 \\
Jul & 24.2 & 166 & 237 & 87 \\
Aug & 24.0 & 145 & 370 & 88 \\
Sep & 24.0 & 148 & 434 & 89 \\
Oct & 23.8 & 171 & 130 & 86 \\
Nov & 23.0 & 175 & 74 & 85 \\
Dec & 21.4 & 169 & 19 & 83 \\
Summary & $23.9 \pm 1.6$ & $2415 \pm$ & $1751 \pm 304^{c}$ & $81.9 \pm 6.0^{b}$ \\
& b & $1099^{\mathrm{c}}$ & & \\
\hline
\end{tabular}

Note:

a Data are averages across 5 years (2004-2008).

${ }^{\mathrm{b}}$ Data are monthly average \pm SD

${ }^{c}$ Data are annual cumulative \pm SD

agricultural area, with coffee plantation and production being the chief economic sector. As this is the most densely populated province in the region and it has a well established system of communicable disease surveillance, it provides an ideal setting for the investigation of dengue and its ecological correlates in the Central Highlands of Vietnam.

Dengue prevention and control activities in Dak Lak province were carried out under a multisectoral dengue action committee. Key activities included surveillance of dengue with routine weekly reports, laboratory-based sentinel surveillance, vector surveillance, and monitoring of environmental risk factors for dengue epidemics. The study was approved by Scientific Committee of Tay Nguyen University.

\section{Surveillance and data collection}

In Dak Lak province, there is a network of 184 commune health stations located in each village. Each station is in charge of communicable disease surveillance. The data are reported first to the district's, then to the province's Center for Preventive Health.

Whenever there is a suspected case of dengue, a standard case management protocol is enacted. According to the protocol, individuals suspected to have dengue are those who meet the WHO case definition (acute febrile illness $\left(\geq 38^{\circ} \mathrm{C}\right)$ of $2-7$ days duration with two or more of the following non-specific manifestations of dengue fever: headache, retro-orbital pain, myalgia, arthralgia, rash, hemorrhagic manifestations, and leucopenia [1]. Once identified the patient is transferred, depending on the severity of the condition, to the 
nearest district hospital or provincial hospital for further diagnosis and treatment. Total numbers of dengue cases were recorded weekly during the surveillance period from 2004 through 2008.

Collection of mosquito larval indices, including the household index $[\mathrm{HI}]$, the container index, and the Breteau index [BI], was conducted monthly from 2004 through 2008. The collection was undertaken in accordance with guidelines recommended by the World Health Organization (WHO) [1]. During the study period, monthly surveys were carried out in 8 sites, 1 in Buon Ma Thuot City and the remaining 7 in various districts in the province. At each time, we randomly selected 8 communes from the list of communes of Buon Ma Thuot City and 7 districts. In each commune, we randomly selected a hamlet, then sampled 100 houses for data collection. The HI was the percentage of houses infested with larvae or pupae [1]. The container index was calculated as percentage of water-holding containers infested with larvae or pupae [1], and the BI was the number of positive container per 100 houses inspected [1].

Meteorological data including temperature $\left({ }^{\circ} \mathrm{C}\right)$, duration of sunshine (hour), amount of rainfall $(\mathrm{mm})$, and relative humidity (\%) were obtained from the local meteorological offices across the province. The data represent monthly averages for each year during the study period from 2004 through 2008.

\section{Data analysis}

The main aim of data analysis was to describe the occurrence of dengue and its association with potential ecological factors. The outcome considered in the analysis was the actual number of dengue cases which was recorded monthly during the study period for all districts of the province. Ecological factors included in the analysis were the $\mathrm{HI}$, the container index, BI, temperature, duration of sunshine, amount of rainfall, and relative humidity.

As the number of reported dengue cases was small relative to the provincial population, distribution of dengue cases was assumed to follow the Poisson distribution. Accordingly, a Poisson regression model was used to model the relationships between the ecological factors and dengue cases. To control for the effect of seasonality and trend, we decomposed the incidence of dengue cases into seasonal and trend series by the classical time series method. In this method, the number of cases $(\mathrm{Y})$ is decomposed into 3 components as follows: $Y_{t}=T_{t}+$ $S_{t}+E_{t}$, where $T_{t}$ denotes the trend component, $S_{t}$ denotes the seasonal component, and $E_{t}$ is the residual component. Because the actual number of dengue cases was small relative to the population, we assumed that the incidence of dengue cases followed a Poisson distribution, with parameter $\lambda_{t}$, i.e., $Y_{t} \sim \operatorname{Poisson}\left(\lambda_{t}\right)$. The effects of ecological covariates were modeled as follows:

$$
\lambda_{t}=\exp \left(\beta_{0}+\beta_{1} X_{t 1}+\beta_{2} X_{t 2}+\beta_{3} X_{t 3}+\ldots+\beta_{p} X_{t p}\right)
$$

where $\beta_{\mathrm{t} 1}, \beta_{\mathrm{t} 2}, \beta_{\mathrm{t} 3}, \ldots, \beta_{\mathrm{tp}}$ are regression coefficients associated with covariates $x_{\mathrm{t} 1}, x_{\mathrm{t} 2}, x_{\mathrm{t} 3}, \ldots, x_{\mathrm{tp}}$, respectively. A time series Poisson regression was then fitted with weather variables, seasonal and trend components. Weather variables were included after performing seasonal difference to control for autocorrelation. First and second order autoregressive terms were considered, but only the first order regressive term was included in the final model because the second term did not reach statistical significance. All analyses were performed using the R package gam [11].

\section{Results}

During the follow-up period (2004 to 2008), 3,502 dengue cases were reported in Dak Lak province. The incidence of dengue strongly fluctuated from year to year, and between months within a year. There was an epidemic in 2004 that accounted for $71.4 \%$ of cases during the surveillance period (Figure 2). The incidence was decreased significantly after 2004. Within a year, the incidence of dengue cases peaked during the JulyOctober period, which falls within the rainy season of May to November (Figure 3). From 2004 through 2008, the total number of dengue cases from the period of July through October accounted for $71.6 \%$ of total cases. The monthly incidence of dengue was correlated with the household index, container index, and Breteau index (Table 2). There was also a significant correlation between Breteau index, household index, and container index.

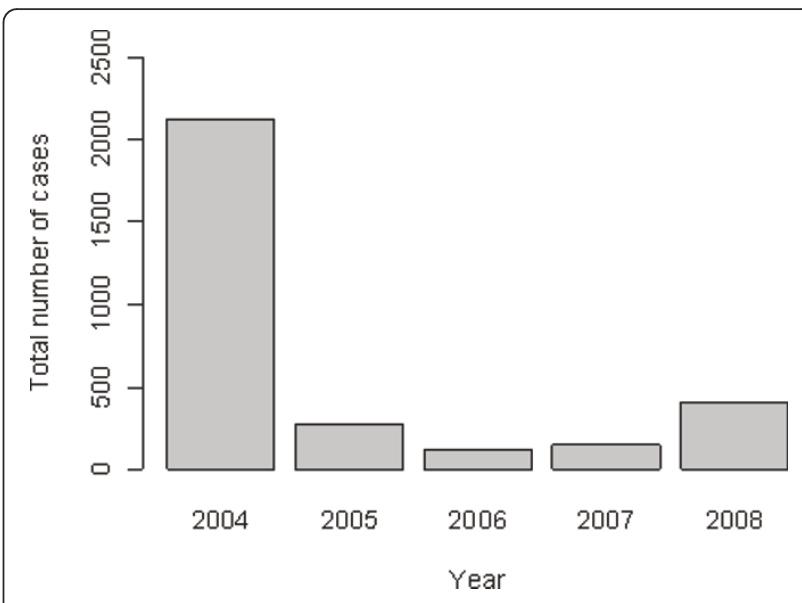

Figure 2 Total number of dengue cases in Dak Lak province, 2004-2008. 


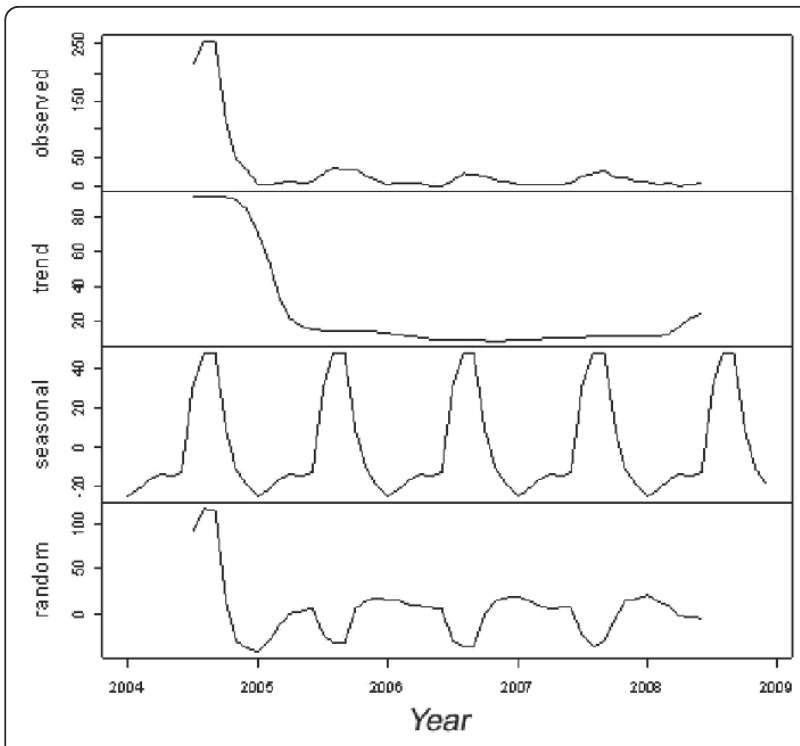

Figure 3 Seasonal and trend decomposition of dengue incidence in Dak Lak province (Vietnam) between 2004 and

2008: Top panel: monthly incidence of dengue; second panel: trend cycles of dengue incidence; third panel: seasonal cycles of dengue; and the bottom panel: random (residual) component.

Results of univariate analysis (Table 3) showed that after adjusting for seasonality, the risk of dengue was significantly associated with increased household index, household mosquito, container index, Breteau index. Moreover, increased temperature, increased rainfall, and increased humidity were each associated with increased risk of dengue. The risk ratio ranged from 1.1 to 1.7. Because these climate and ecological variables were correlated, a multivariable Poisson regression model was fitted to the data to search for independent factors

Table 2 Monthly mosquito indices and occurrence of dengue in Dak Lak province

\begin{tabular}{ccccc}
\hline Month & $\begin{array}{c}\text { House } \\
\text { Index }\end{array}$ & Container Index & $\begin{array}{c}\text { a } \\
\text { Breteau } \\
\text { Index }^{\mathbf{a}}\end{array}$ & ${\text { No. of } \text { cases }^{\mathbf{b}}}$ \\
\hline Jan & 3.7 & 2.9 & 4.8 & 27 \\
Feb & 4.2 & 3.3 & 5.4 & 20 \\
Mar & 3.9 & 3.4 & 5.4 & 22 \\
Apr & 4.6 & 3.4 & 5.9 & 43 \\
May & 5.6 & 4.1 & 6.9 & 183 \\
Jun & 6.6 & 4.9 & 9.1 & 302 \\
Jul & 7.0 & 5.5 & 10.1 & 448 \\
Aug & 7.4 & 5.8 & 10.1 & 593 \\
Sep & 7.4 & 5.8 & 9.6 & 1007 \\
Oct & 7.1 & 6.2 & 9.7 & 459 \\
Nov & 5.6 & 3.9 & 6.9 & 281 \\
Dec & 4.7 & 3.2 & 5.7 & 117 \\
\hline
\end{tabular}

Notes:

a Data are averages across 5 years (2004-2008).

${ }^{\mathrm{b}}$ Data are total number of cases tallied from 2004 to 2008.
Table 3 Risk factors for dengue incidence in Dak Lak province: univariate analysis

\begin{tabular}{llll}
\hline Risk factor & Unit of comparison & $\begin{array}{l}\text { Risk ratio } \\
(\mathbf{9 5 \%} \text { Cl) }\end{array}$ & P-value \\
\hline Household index & Per 5\% increase & $1.66(1.62-1.70)$ & $<0.0001$ \\
Household mosquito & Per 5\% increase & $1.16(1.14-1.18)$ & $<0.0001$ \\
Container index & Per 5\% increase & $1.78(1.73-1.83)$ & $<0.0001$ \\
Breteau index & Per 5 unit increase & $1.57(1.53-1.60)$ & $<0.0001$ \\
\hline Temperature & Per 2 ${ }^{\circ} \mathrm{C}$ increase & $1.39(1.25-1.55)$ & $<0.0001$ \\
Sunshine & Per 50 hours increase & $0.76(0.73-0.79)$ & $<0.0001$ \\
Rainfall & Per 50 mm increase & $1.13(1.21-1.74)$ & $<0.0001$ \\
Humidity & Per 5\% increase & $1.59(1.51-1.67)$ & $<0.0001$ \\
\hline
\end{tabular}

(Table 4). Results of the multivariable analysis indicated that the risk of dengue was independently associated with higher household index (RR: 1.87; 95\% CI: 1.811.93 per $5 \%$ increase), higher mosquito index (RR: 1.08 ; 95\% CI: $1.06-1.11$ per $5 \%$ increase), increased rainfall (RR: $1.14 ; 95 \%$ CI: $1.12-1.15$ per $50 \mathrm{~mm}$ ), and increased temperature (RR 1.21; 95\% CI: 1.11-134).

\section{Discussion}

Previous studies have shown that the dynamics of dengue is affected by many factors, including environmental and climate factors, host-vector interactions and the herd immunity [12-15]. Climate factors may directly or indirectly affect vector survival, lifespan, development and reproductive rates that could influence dengue spatio-temporal distributions [7,16-19]. The present study demonstrated a clear seasonal pattern of dengue occurrence in a Central Highlands province of Vietnam, with the highest number of cases occurring in the rainy season. Elevated temperature, relative humidity and duration of sunshine were also associated with an increased occurrence of dengue.

Our result is consistent with previous studies which found that the majority of dengue cases occurred in months with higher rainfall that were clearly defined "dengue season" [8,20-22]. In Trinidad, "dengue season" was between June and November [23], and evidence showed that the dengue incidence in Metro Manila varies with changing rainfall patterns [24]. It has been hypothesized that rainfall affects adult female mosquito density. An increase in amount of rainfall leads to more

Table 4 Risk factors for dengue incidence in Dak Lak province: multivariate analysis

\begin{tabular}{llll}
\hline Risk factor & Unit of comparison & $\begin{array}{l}\text { Risk ratio } \\
(\mathbf{9 5 \%} \mathbf{C l})\end{array}$ & P-value \\
\hline Household index & Per 5\% increase & $1.87(1.81-1.93)$ & $<0.0001$ \\
Household mosquito & Per 5\% increase & $1.08(1.06-1.11)$ & $<0.0001$ \\
\hline Temperature & Per $2^{\circ} \mathrm{C}$ increase & $1.21(1.10-1.34)$ & $<0.0001$ \\
Rainfall & Per $50 \mathrm{~mm}$ increase & $1.14(1.12-1.15)$ & $<0.0001$ \\
\hline
\end{tabular}


breeding sites which, in turn, lead to an increase in the number of mosquitoes. An increase in the number of adult female mosquitoes increases the probability of viral transmission [25]. Elevated temperature is associated with an increased incidence of dengue due to accelerated development rate of the virus and increased mosquito biting rate [26], as well as increased development rate of different mosquito life stages and dengue virus replication. Higher temperature enhances virus replication and shorten the extrinsic incubation period in the vector [27] whereas higher relative humidity decreases adult mosquito mortality [21].

In Dak Lak province, we found that the rainy season is characterized by a higher $\mathrm{BI}$, container index, and $\mathrm{HI}$, which is also consistent with a previous observation that a positive associations between the incidence of dengue and the Aedes HI and the BI [21,28]. This relationship suggests that the latter might have exerted its effect on dengue infection partly through the creation of more breeding sites for $A$. aegypti. Surveillance by ovitrap (a device consisting of a black painted milk can, filled with $250 \mathrm{ml}$ tap water and a hole each side of tin) in a selected urban area and suburban area in Malaysia for 14 months found a strong correlation between rainfall and egg population [29]. A retrospective ecological study on impact of weather variables and climatic indicators associated with the incidence of dengue conducted in Mexico from 1995 to 2003 showed that increases in weekly minimum temperature and rainfall were also significant factors in the increase in the reported cases of dengue [30]. A study in Barbados has documented a correlation between the incidence of dengue in a specific parish from 1995-2000, and a range of climate variables, with lags from 7-16 weeks [31]. A study in 14 provinces of southern Thailand indicated that the temperature, rainfall and humidity were associated with dengue hemorrhagic fever incidence [32].

The present study should be interpreted within the context of strengths and limitations. In the province, health workers at all levels are very familiar with dengue fever and dengue hemorrhagic fever, as proven by the low case-fatality rate [2] and the standard clinical case definition for dengue has been used for more than 10 years without substantial change [1]. Dengue diagnosis is based on standard clinical case definition of WHO for identifying outbreak and initiating an early response as well as reducing dengue mortality. However, a recent study on dengue diagnosis using WHO's standard clinical case definition for dengue showed high sensitivity but poor specificity [33]. Therefore, there existed a possibility of overestimation of the number of dengue cases in the study. However, to our knowledge, there were a number of dengue patients treated in private health services that could not recorded. Indeed. a study of diagnosis of acute undifferentiated fever in Vietnam showed that acute dengue was found in $\sim 34 \%$ cases, which suggests that the possibility of underreporting of dengue in commune health stations [34]. The present study was an ecological investigation; therefore, it is not possible to make inference concerning the causative relationship between the mosquito larval indices and dengue infection at the individual patient level. The number of deaths was small and therefore not suitable for a thorough analysis of risk factors for dengue mortality.

\section{Conclusions}

In summary, our study in the Central Highlands of Vietnam showed that the risk of dengue increased during rainy months when monthly rainfall increased together with the increased vector population as indicated by the monthly HI, container index and BI. The global climate change will likely increase the burden of dengue fever infection in Vietnam. Intensified surveillance and control of mosquito during high temperature and rainfall seasons may be an effective strategy for containing the burden of dengue fever.

\section{Acknowledgements}

We thank Tuan Van Nguyen for assistance in statistical analysis and review of the manuscript. We acknowledge the technical and financial assistance of Institute of Hygiene and Epidemiology of Tay Nguyen, and the Center for Preventive Health of Dak Lak province, Vietnam.

\section{Author details}

${ }^{1}$ Institute of Hygiene and Epidemiology of Tay Nguyen, Dak Lak, Vietnam. ${ }^{2}$ Vietnam Field Epidemiology Training Programme (FETP), Hanoi, Vietnam.

\section{Authors' contributions}

HVP and HTMD designed the study, performed data analysis, interpretation and drafted the manuscript. HVP, HTMD and TTP contributed to the collection, entry, analysis and interpretation of data. HVP and NNTM performed data analysis, interpretation and wrote the manuscript. All authors read and approved the final version of the manuscript.

\section{Competing interests}

The authors declare that they have no competing interests.

Received: 12 January 2011 Accepted: 16 June 2011

Published: 16 June 2011

\section{References}

1. WHO: Dengue: guidelines for diagnosis, treatment, prevention and control Geneva; 2009.

2. WHO: Dengue and dengue haemorrhagic fever. Health in Asia and the Pacific 2008, 00:244-255.

3. Hales S, de Wet N, Maindonald J, Woodward A: Potential effect of population and climate changes on global distribution of dengue fever: an empirical model. Lancet 2002, 360(9336):830-834.

4. Russell RC: Mosquito-borne disease and climate change in Australia: time for reality check. Australian Journal of Entomology 2009, 48:1-7.

5. WHO: WHO. Revision of the International Health Regulations. World Health Assembly Resolution WHA583, adopted by the 58th World Health Assembly: 20052005.

6. Arunachalam N, Tana S, Espino F, Kittayapong P, Abeyewickreme W, Wai KT, Tyagi BK, Kroeger A, Sommerfeld J, Petzold M: Eco-bio-social determinants 
of dengue vector breeding: a multicountry study in urban and periurban Asia. Bull World Health Organ 2010, 88(3):173-184.

7. Hu W, Clements A, Williams G, Tong S: Dengue fever and El Nino/ Southern Oscillation in Queensland, Australia: a time series predictive model. Occup Environ Med 2010, 67(5):307-311.

8. Kuhn K, Campbell-Lendrum D, Haines A, Cox J: Using climate to predict infectious disease epidemics. Geneva: WHO; 2005

9. Hales S, Weinstein P, Souares Y, Woodward A: El Nino and the dynamics of vectorborne disease transmission. Environ Health Perspect 1999, 107(2):99-102

10. Gurtler RE, Garelli FM, Coto HD: Effects of a five-year citywide intervention program to control Aedes aegypti and prevent dengue outbreaks in northern Argentina. PLoS Negl Trop Dis 2009, 3(4):e427.

11. R Development Core Team: R: A language and environment for statistical computing. 2007.

12. Thammapalo S, Chongsuwiwatwong V, McNeil D, Geater A: The climatic factors influencing the occurrence of dengue hemorrhagic fever in Thailand. Southeast Asian J Trop Med Public Health 2005, 36(1):191-196.

13. Johansson MA, Cummings DA, Glass GE: Multiyear climate variability and dengue-El Nino southern oscillation, weather, and dengue incidence in Puerto Rico, Mexico, and Thailand: a longitudinal data analysis. PLoS Med 2009, 6(11):e1000168.

14. Nagao $\mathrm{Y}$, Koelle $\mathrm{K}$ : Decreases in dengue transmission may act to increase the incidence of dengue hemorrhagic fever. Proc Natl Acad Sci USA 2008, 105(6):2238-2243.

15. Tabachnick WJ: Challenges in predicting climate and environmental effects on vector-borne disease episystems in a changing world. J Exp Biol 2010, 213(6):946-954

16. Halstead S: Dengue virus-mosquito interactions. Annu Rev Entomol 2008 , 53:273-291.

17. Githeko AK, Lindsay SW, Confalonieri UE, Patz JA: Climate change and vector-borne diseases: a regional analysis. Bull World Health Organ 2000, 78(9):1136-1147.

18. Thai KT, Cazelles B, Nguyen NV, Vo LT, Boni MF, Farrar J, Simmons CP, van Doorn HR, de Vries PJ: Dengue dynamics in Binh Thuan province, southern Vietnam: periodicity, synchronicity and climate variability. PLoS Negl Trop Dis 2010, 4(7):e747.

19. Yang HM, Macoris ML, Galvani KC, Andrighetti MT, Wanderley DM: Assessing the effects of temperature on dengue transmission. Epidemiol Infect 2009, 137(8):1179-1187.

20. Wiwanitkit V: An observation on correlation between rainfall and the prevalence of clinical cases of dengue in Thailand. $J$ Vector Borne Dis 2006, 43(2):73-76.

21. Hopp MJ, Foley JA: Worldwide fluctuations in dengue fever cases related to climate variability. Climate Research 2003, 25:85-94.

22. Li CF, Lim TW, Han LL, Fang R: Rainfall, abundance of Aedes aegypti and dengue infection in Selangor, Malaysia. Southeast Asian I Trop Med Public Health 1985, 16(4):560-568

23. Chadee DD, Shivnauth B, Rawlins SC, Chen AA: Climate, mosquito indices and the epidemiology of dengue fever in Trinidad (2002-2004). Ann Trop Med Parasitol 2007, 101(1):69-77.

24. Su GL: Correlation of climatic factors and dengue incidence in Metro Manila, Philippines. Ambio 2008, 37(4):292-294.

25. Wongkoon S, Jaroensutasinee M, Jaroensutasinee K, Preechaporn W, Chumkiew S: Larval occurrence and climatic factors affecting DHF incidence in Samui Islands, Thailand. World Academy of Science, Engineering and Technology 2007, 33:5-10.

26. Patz JA, Martens WJM, Focks AA, Jetten TH: Dengue Fever Epidemic Potential as Projected by General Circulation Models of Global Climate Change. Environmental Health Perspectives 1998, 6(3):147-153.

27. Bangs MJ, Larasati RP, Corwin AL, Wuryadi S: Climatic factors associated with epidemic dengue in Palembang, Indonesia: implications of shortterm meteorological events on virus transmission. Southeast Asian J Trop Med Public Health 2006, 37(6):1103-1116.

28. Wongkoon S, Jaroensutasinee M, Jaroensutasinee K: Larval Infestations of Aedes aegypti and Ae. albopictus in Nakhonsrithammarat, Thailand. Dengue Bulletin 2005, 29:169-175.

29. Rozilawati H, Zairi J, Adanan CR: Seasonal abundance of Aedes albopictus in selected urban and suburban areas in Penang, Malaysia. Trop Biomed 2007, 24(1):83-94.
30. Hurtado-Diaz M, Riojas-Rodriguez H, Rothenberg SJ, Gomez-Dantes H, Cifuentes E: Short communication: impact of climate variability on the incidence of dengue in Mexico. Trop Med Int Health 2007, 12(11):1327-1337.

31. Depradine C, Lovell E: Climatological variables and the incidence of Dengue fever in Barbados. Int J Environ Health Res 2004, 14(6):429-441.

32. Promprou S, Jaroensutasinee M, Jaroensutasinee K: Climatic factors affecting dengue haemorrhagic fever incidence in Southern Thailand. Dengue Bulletin 2005, 29:41-48.

33. Chaterii S, Allen JC Jr, Chow A, Leo YS, Ooi EE: Evaluation of the NS1 rapid test and the WHO dengue classification schemes for use as bedside diagnosis of acute dengue fever in adults. Am J Trop Med Hyg 2011, 84(2):224-228

34. Phuong HL, de Vries PJ, Nga TT, Giao PT, Hung le Q, Binh TQ, Nam NV, Nagelkerke N, Kager PA: Dengue as a cause of acute undifferentiated fever in Vietnam. BMC Infect Dis 2006, 6:123.

Pre-publication history

The pre-publication history for this paper can be accessed here: http://www.biomedcentral.com/1471-2334/11/172/prepub

doi:10.1186/1471-2334-11-172

Cite this article as: Pham et al: Ecological factors associated with dengue fever in a central highlands Province, Vietnam. BMC Infectious Diseases 2011 11:172.

\section{Submit your next manuscript to BioMed Central and take full advantage of:}

- Convenient online submission

- Thorough peer review

- No space constraints or color figure charges

- Immediate publication on acceptance

- Inclusion in PubMed, CAS, Scopus and Google Scholar

- Research which is freely available for redistribution

Submit your manuscript at www.biomedcentral.com/submit
Ciomed Central 